\title{
Herpetic keratitis in Tanzania: association with malaria
}

\author{
David Yorston, Allen Foster
}

\begin{abstract}
Of 103 patients who presented to a rural clinic in Africa with corneal ulceration, $62(60.2 \%)$ had corneal ulcers which on clinical diagnosis were attributable to herpes simplex virus. There was a strong association between herpetic ulceration and a history of recent malaria; 37 of $62(59.7 \%)$ herpetic ulcers occurred in the 3 month period from April to June which corresponds to the end of the peak season for malaria compared with 14 of 41 (34\%) of the non-herpetic ulcers. Fifty per cent of herpetic ulcers had a geographic morphology, $27.4 \%$ were dendritic, and $22.6 \%$ presumed herpetic ulcers were stromal: $38 \cdot 7 \%$ of herpetic ulcers occurred in children under 5 years of age. Bilateral herpetic ulcers occurred in $16.1 \%$ of patients but were more common in children under 2 years of age. Geographic and stromal ulcers tended to heal more slowly than dendritic ulcers (mean time to healing 12.6, 12.2 , and 6.6 days respectively), and were more likely to result in severe corneal scarring $(45 \%, 29 \%$, and $0 \%$ respectively). Herpes simplex keratitis is a major cause of corneal scarring in Africa. It is often seen in children, may be bilateral, commonly is geographic in morphology, and has a strong association with malaria infection. Because it is not easily preventable, more effort must be made to ensure early diagnosis and prompt, effective treatment in order to prevent severe scarring and visual loss.
\end{abstract}

(Br F Ophthalmol 1992; 76: 582-585)

It has been known for over a decade that herpes simplex virus (HSV) type 1 can produce severe corneal ulceration in children in both west and east Africa, particularly in relation to measles ${ }^{1-3}$; however there have been few reports of herpetic ulceration in adults.

In industrialised countries the commonest form of HSV ulcer is the dendritic pattern, in which viral replication is confined to the epithelium, and which usually heals with little or no corneal scarring. Geographic and stromal ulcers do occur, most commonly in immunosuppressed patients, or following the inappropriate use of topical steroids. ${ }^{+}$In Africa, severe geographic or stromal ulceration which is presumed to be due to HSV, on account of its morphological appearance and response to specific antiviral therapy, appears to be the norm rather than the exception. As a result, HSV keratitis is even more important as a cause of ocular morbidity and visual loss in Africa than in developed countries. This study was undertaken in order to investigate the characteristics of corneal ulcers presumed to be caused by HSV in Tanzania.

\section{Methods}

A prospective study evaluated all patients presenting to the Mvumi Hospital eye clinic between April 1988 and March 1989 inclusive. Mvumi hospital is a mission hospital situated 40 $\mathrm{km}$ south east of Dodoma in the centre of Tanzania. The area is arid and infertile, and is known as one of the poorest regions of the country. The rains occur from January to April, and are associated with a seasonal malaria epidemic. Trachoma and bacterial conjunctivitis are very common.

Patients presenting with corneal ulceration were examined by one ophthalmologist (DY). Details were recorded, including information regarding any recent episode of malaria, or use of traditional eye medicines (TEM) within the previous 2 weeks. The patients underwent ocular examination, including slit-lamp biomicroscopy. Corneal ulcers were drawn and photographed. The patients were admitted and treated appropriately according to the clinical diagnosis.

The diagnosis was made on clinical grounds as laboratory confirmation was not possible in this setting. Patients with clinical HSV keratitis were categorised, depending on the predominant morphology of their ulcers, as having dendritic, geographic, or stromal ulceration (Figs 1, 2, 3). The clinical characteristics and morphological appearances of laboratory proved herpetic ulceration have been previously reported.'Patients with HSV keratitis were treated with idoxuridine (IDU) ointment five times per day, and atropine drops every 8 hours. Topical and subconjunctival antibiotics were only given if there was evidence of secondary bacterial infection, such as a hypopyon or purulent discharge. The response to specific treatment with

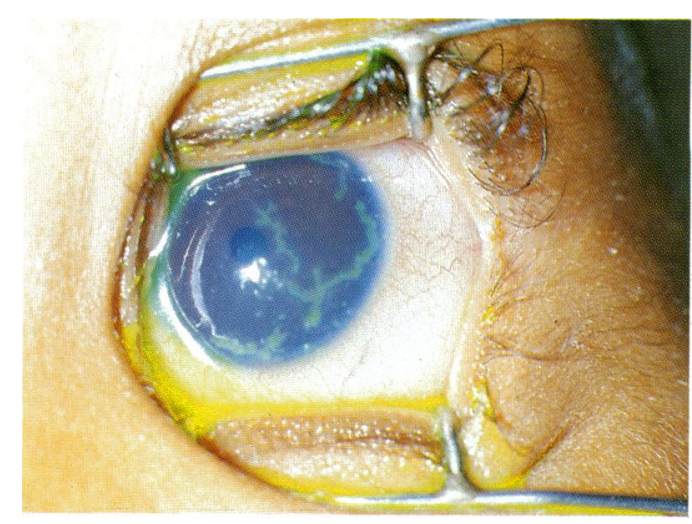

Figure 1 Dendritic type corneal ulceration. 


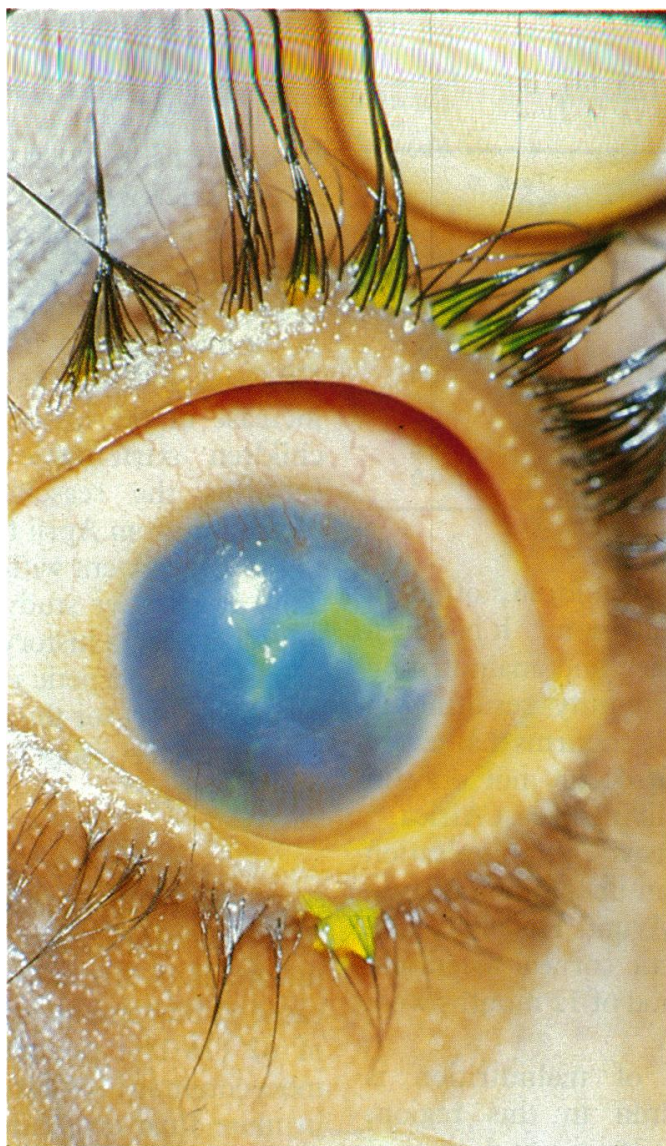

Figure 2. Geographic type comeal ulceration with vascularisation and stromal oedema.

idoxuridine ointment was also used to confirm the diagnosis of clinical herpetic keratitis (Figs 3 and 4). The patients remained in hospital and were examined daily until their ulcers healed. The time to healing, defined as 'no corneal staining with fluorescein', was recorded for all ulcers.

The outcome of the ulceration was graded according to the severity of corneal scarring at discharge: grade A - no or slight scarring, defined as corneal opacity that did not obscure the underlying iris detail; grade B - moderate scarring - a corneal opacity obscuring the iris detail but not in the visual axis; grade $\mathrm{C}$ - severe scarring, a corneal opacity in the visual axis which obscures the iris.

\section{Results}

Presumed HSV was rèsponsible for $62(60 \cdot 2 \%$, 95\% confidence limit (CL) 50.6-69.8\%) corneal ulcers in this study. Use of TEM can result in

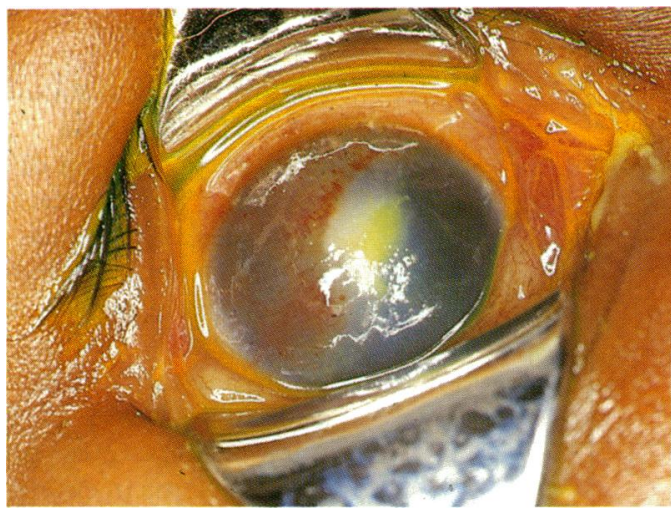

Figure 3 Stromal ulceration and severe vascularisation due to presumed herpetic keratitis.

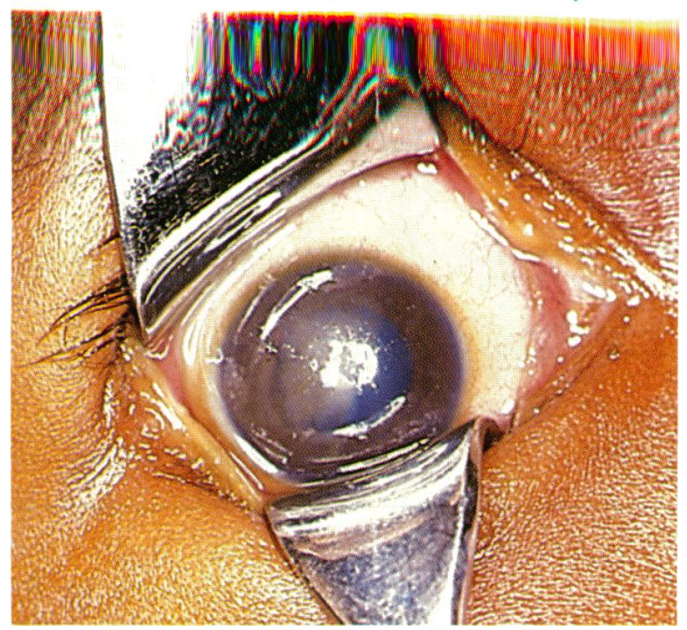

Figure 4 The same patient as in Figure 3 after 2 weeks of antiviral therapy with idoxuridine ointment five times per day.

severe corneal ulceration and was directly responsible for $15 \%$ of all corneal ulcers in this study. It was also used in a further $10 \%$ of corneal ulcers due to other causes. (Table 1).

Of the 62 ulcers attributed to herpes simplex $50 \%$ were geographic in morphology, 23\% stromal (presumed herpetic) and 27\% dendritic (Fig 5). Eight patients with herpetic ulceration gave a history of using TEM (13\%), of whom five had an associated hypopyon.

Fifty four of $62(87 \cdot 1 \%)$ patients with herpetic ulceration gave a history of malaria in the preceding 2 weeks compared with nine of 41 $(21.9 \%)$ patients with non-herpetic ulcers $(\mathrm{p}<0.001)$. A seasonal variation was noted with 37 of $62(60 \%)$ of the herpetic corneal ulcers occurring in the 3 months from April to June, compared with 14 of 41 (34\%) of the non herpetic ulcers $(\mathrm{p}=0 \cdot 01$ ) (Fig 6).

Twenty four of $62(38 \cdot 7 \%, 95 \% \mathrm{CL}, 29 \cdot 1 \%$ $48.3 \%$ ) of the herpetic ulcers occurred in children aged $0-4$ years and nine of $62(14.5 \%)$ in children aged 5-10 years. A total of 54 of 62 $(87 \cdot 1 \%)$ occurred in patients under 30 years of age. In children aged 0-2 years seven of 19 (36.8\%) herpetic ulcers were bilateral compared with three of $43(7 \%)$ in all other age groups $(p=0.003)$.

There was an excess of females $(37: 25)$ in the herpetic group but this was not seen in nonherpetic ulcers $(18: 23)$, although this did not reach statistical significance $(p=0 \cdot 12)$. Five patients $(8 \%)$ all aged under 2 years had associated herpetic skin ulcers.

The mean times to healing of the different morphological types of ulcers were geographic 12.6 days (95\% CL, $10 \cdot 0-15 \cdot 2)$; stromal 12.2 days $(95 \% \mathrm{CL}, 6 \cdot 2-18 \cdot 2)$; and dendritic 6.6 days (95\% CL, 5.3-7.9). The time taken to heal was not related to the age of the patient.

The outcome in patients with herpetic corneal ulcer was classified as minimal or no corneal scarring (A) in $40.3 \%$; moderate scarring $(B)$ in $30.6 \%$; and severe scarring (C) in $29 \%$. Severe scarring was a more frequent outcome in geographic ulcers $(45 \cdot 2 \%)$ and stromal ulcers $(28 \%)$ than dendritic ulcers ( $0 \%$ ) (Table 2 ).

\section{Discussion}


Table 1 Aetiology of corneal ulceration in 103 patients, Mvumi, Tanzania

\begin{tabular}{|c|c|c|c|c|c|c|}
\hline $\begin{array}{l}\text { Cause } \\
\text { Herpes simplex }\end{array}$ & \multicolumn{2}{|c|}{$\underset{n}{\text { Unilateral }}$} & \multicolumn{2}{|c|}{$\underset{n}{\text { Bilateral }} \%$} & $\begin{array}{l}\frac{T}{n} \text { Total } \\
62\end{array}$ & $\frac{\%}{60 \cdot 3}$ \\
\hline $\begin{array}{l}\text { Herpes simplex } \\
\text { Traditional eye medicines } \\
\text { Bacterial } \\
\text { Xerophthalmia } \\
\text { Mooren's ulcer } \\
\text { Trichiasis } \\
\text { Exposure } \\
\text { Other } \\
\text { Unknown } \\
\text { Total }\end{array}$ & $\begin{array}{r}52 \\
15 \\
7 \\
0 \\
0 \\
2 \\
0 \\
5 \\
3 \\
84\end{array}$ & $\begin{array}{r}61 \cdot 8 \\
17 \cdot 9 \\
8 \cdot 3 \\
0 \cdot 0 \\
0 \cdot 0 \\
2 \cdot 4 \\
0 \cdot 0 \\
6 \cdot 0 \\
3 \cdot 6 \\
100 \cdot 0\end{array}$ & $\begin{array}{r}10 \\
0 \\
2 \\
3 \\
2 \\
0 \\
1 \\
1 \\
0 \\
19\end{array}$ & $\begin{array}{r}52 \cdot 6 \\
0 \cdot 0 \\
10 \cdot 5 \\
15 \cdot 8 \\
10 \cdot 5 \\
0 \cdot 0 \\
5 \cdot 3 \\
5 \cdot 3 \\
0 \cdot 0 \\
100 \cdot 0\end{array}$ & $\begin{array}{r}62 \\
15 \\
9 \\
3 \\
2 \\
2 \\
1 \\
6 \\
3 \\
103\end{array}$ & $\begin{array}{r}60 \cdot 3 \\
14 \cdot 6 \\
8 \cdot 7 \\
2 \cdot 9 \\
1 \cdot 9 \\
1 \cdot 9 \\
1 \cdot 0 \\
5 \cdot 8 \\
2 \cdot 9 \\
100 \cdot 0\end{array}$ \\
\hline
\end{tabular}

herpetic ulcers in African children, often in relation to measles or malnutrition..$^{1-3}$ It has been suggested that both measles and malnutrition depress cell mediated immunity resulting in severe ulceration. This study confirms that severe herpetic corneal ulcers do occur, not only in children but also in adults living in east Africa.

Following an intensive immunisation campaign measles is now an uncommon disease in the area surrounding Mvumi Hospital, ${ }^{5}$ and none of the cases of herpetic corneal ulceration seen during this study period of 12 months were related to measles infection.

Though some degree of malnutrition is widespread among children in this region, especially during weaning, significant degrees of protein-calorie malnutrition are uncommon among adults, except during serious famines. As a result the occurrence of severe HSV corneal ulceration in adults, as reported in this study, is unlikely to be attributable to either measles or malnutrition.

An increasingly common cause of immunodeficiency in Africa is infection with the human immunodeficiency virus (HIV). HIV serology was not performed on any of the patients included in this study. The two peaks in the incidence of herpetic ulcers, in children and in young adults, correspond to the populations known to be at greatest risk of HIV infection in Africa. Although no population based survey of HIV seropositivity has been carried out it was not thought to exceed $1 \%$ of the population in this rural part of Tanzania at the time of this study.

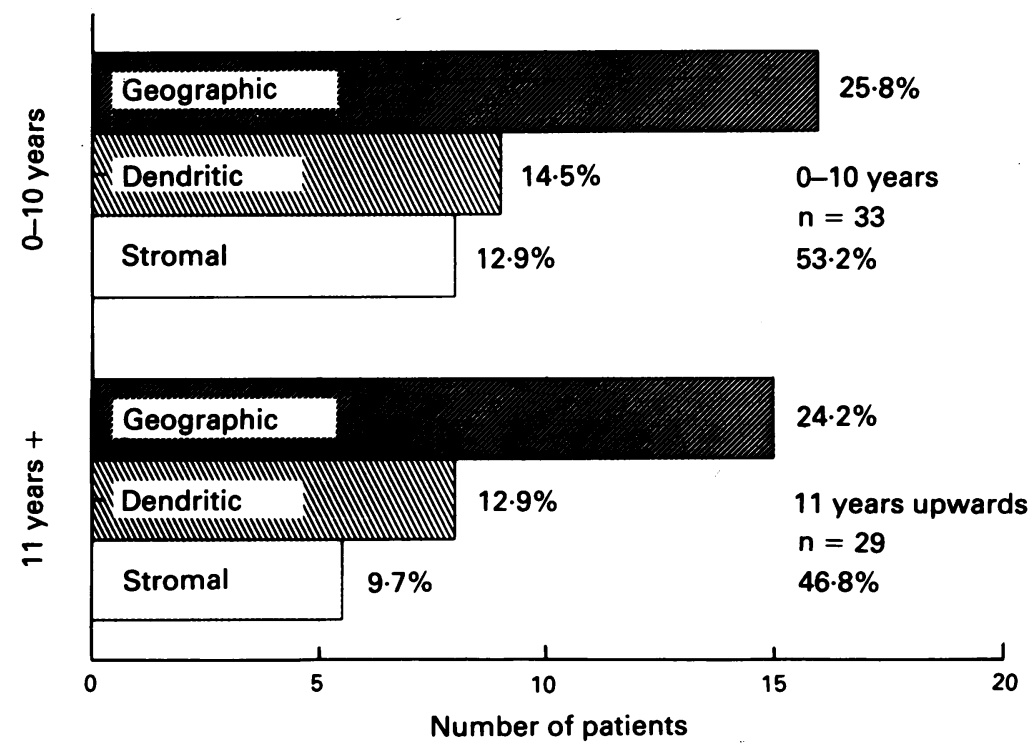

Figure 5 Morphology of 62 corneal ulcers due to HSV by age in Mvumi, Tanzania.
Topical steroids are not available outside the major towns in Tanzania, and are unlikely to be responsible for the severe HSV ulceration seen in these patients, almost all of whom came from small villages.

We have previously reported ${ }^{6}$ that an increase in the incidence of malaria at Mvumi between February and May has been associated with an increase in the incidence of corneal ulcers in children attributable to HSV. This study confirms the seasonal increase in herpetic ulceration from April to June, which is not seen to the same extent with non-herpetic ulceration. This prospective study demonstrates an association between a history of recent malaria, and a diagnosis of herpetic corneal ulceration further giving support for the hypothesis that malaria is a major predisposing factor for herpetic keratitis in this area.

OUTCOME OF HERPETIC KERATITIS IN AFRICA

Although HSV ulcers are characteristically unilateral, in this study HSV was the commonest cause of bilateral ulceration, occurring in 10 out of $62(16 \cdot 1 \%)$ patients. Bilateral ulcers were more common in children under 2 years occurring in more than one third of those with herpetic ulcers. This may be related to nutrition which is more likely to be inadequate in young children.

Twenty nine percent of patients with herpetic ulceration developed scarring of a severity sufficient to reduce the visual acuity (grade C). Nearly half $(45 \cdot 2 \%)$ of patients with geographic ulcers had visually disabling scarring, affecting the central cornea. It has been estimated that half of all patients with HSV corneal ulcers will develop further recurrences within the following 2 years. $^{7}$ This suggests that in the years to come, many of the patients included will suffer a reduction in their visual acuity as a result of herpetic keratitis.

It has been shown that corneal scarring is the commonest cause of blindness in children in east Africa, occurring in $70 \%$ of children in blind schools. ${ }^{89}$ As effective primary health care programmes succeed in reducing the incidence of corneal scarring from vitamin A deficiency and measles it is possible that herpetic keratitis will become the leading cause of visual loss owing to corneal ulceration in African children. Since corneal grafting is not yet feasible in most parts of the continent, strategies to reduce visual loss from HSV to a minimum should be identified.

\section{PREVENTION AND MANAGEMENT OF HERPETIC} KERATITIS IN AFRICA

Primary prevention of HSV infection is not yet possible, but research into possible vaccines continues. Avoidance of known precipitating factors, such as malaria, may have a role but prevention of malaria is not easy in rural African communities. Measles immunisation, and improved nutrition in young children, which are already included in most community health interventions, may prevent some episodes of HSV keratitis in children.

Secondary prevention through early and effective treatment with anti-virals would seem a 


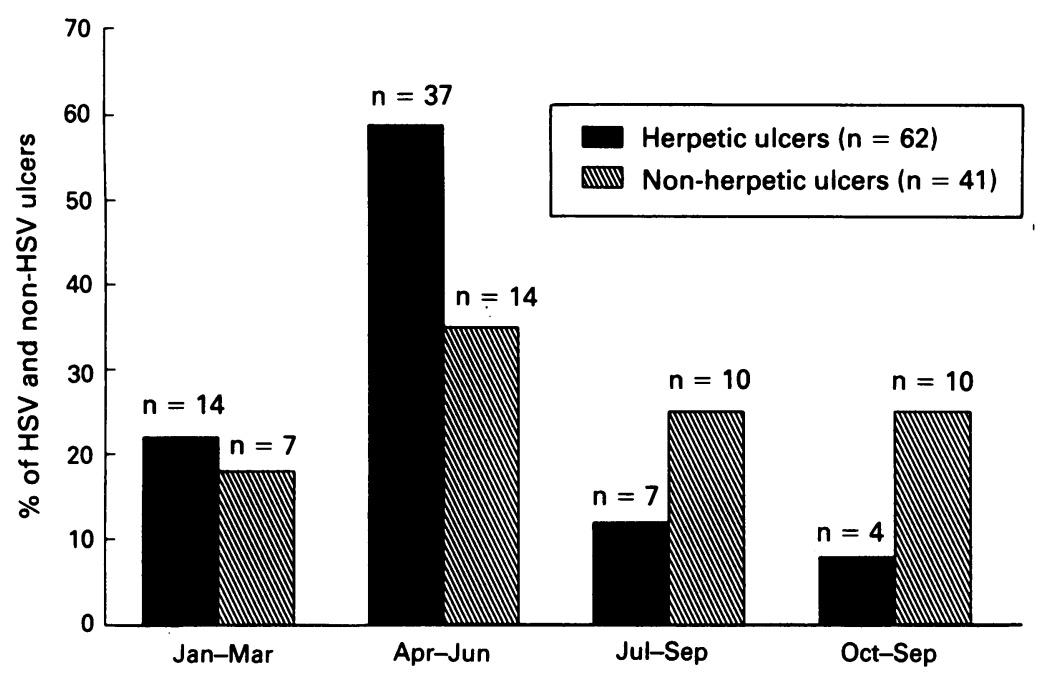

Figure 6 Corneal ulceration by cause and season in Mvumi, Tanzania.

reasonable possibility. This implies early diagnosis, which requires that the patient is examined promptly by an eye-trained medical worker. Unfortunately on average for every one million Africans there is only one ophthalmologist, and he or she is usually located in the large cities, out of reach of the rural population. ${ }^{10}$ Training of more ophthalmic workers, at all levels, is a high priority for prevention of blindness in Africa.

Early diagnosis is of little benefit unless effective treatment is available and, unfortunately, local preparation of idoxuridine eye drops is difficult. " Idoxuridine ointment has toxic effects on the cornea and ocular surface if used for long periods, and costs about $£ 1$ for a $5 \mathrm{~g}$ tube. This is more than the per capita health budget of some African countries. Acyclovir has fewer adverse effects than idoxuridine, but is even more expensive. In Tanzania, idoxuridine ointment is only available at a few of the larger hospitals, which receive substantial support from foreign donor agencies. Mechanical debridement can be effective in the treatment of dendritic ulcers, ${ }^{12}$ but is contraindicated in geographic and stromal ulceration. Mechanical debridement is also dif-

Table 2 Outcome in patients with herpetic corneal ulceration by morphology

\begin{tabular}{|c|c|c|c|c|c|c|c|c|}
\hline Outcome & \multicolumn{2}{|c|}{$\underset{n}{\text { Dendritic }} \%$} & \multicolumn{2}{|c|}{ Geographic } & \multicolumn{2}{|c|}{$\begin{array}{l}\text { Stromal } \\
n\end{array}$} & $\begin{array}{l}\text { Total } \\
n\end{array}$ & $\%$ \\
\hline $\begin{array}{l}\text { A } \\
\text { B } \\
\text { C }\end{array}$ & $\begin{array}{r}16 \\
1 \\
0 \\
17\end{array}$ & $\begin{array}{r}94.1 \\
5.9 \\
0.0\end{array}$ & $\begin{array}{r}8 \\
9 \\
14 \\
31\end{array}$ & $\begin{array}{l}25 \cdot 8 \\
29 \cdot 0 \\
45 \cdot 2\end{array}$ & $\begin{array}{r}1 \\
9 \\
4 \\
14\end{array}$ & $\begin{array}{r}7 \cdot 1 \\
64 \cdot 3 \\
28 \cdot 6\end{array}$ & $\begin{array}{l}25 \\
19 \\
18 \\
62\end{array}$ & $\begin{array}{r}40 \cdot 3 \\
30 \cdot 6 \\
29 \cdot 1 \\
100 \cdot 0\end{array}$ \\
\hline
\end{tabular}

ficult to perform adequately in young children without resorting to general anaesthesia.

There is some laboratory work which suggests that povidone iodine $1 \%$ drops may be effective against $\mathrm{HSV} .{ }^{13}$ Povidone iodine is inexpensive, and a $1 \%$ drop can be made easily from the commercially available $10 \%$ solution. ${ }^{11}$ Further work is in progress to evaluate PVI in the treatment of $\mathrm{HSV}$. corneal ulceration, and to assess any adverse effects of regular topical use.

\section{Conclusion}

Herpetic corneal ulcers are a common and serious cause of ocular morbidity in Africa. It is likely that malaria, malnutrition, measles, and late presentation are just some of the factors responsible for the aggressive pattern of disease seen in HSV corneal ulceration in Africa compared to Europe. At present, African patients with herpetic keratitis have little hope of receiving early or effective treatment. There is an urgent need for more eye-trained medical workers and for inexpensive, but effective, anti-herpetic drugs.

The authors would like to acknowledge the generous support of Christoffel-Blindenmission, Germany which made this work possible.

1 Foster A, Sommer A. Corneal ulceration, measles, and childhood blindness in Tanzania. Brf Ophthalmol 1987; 71: 331-43.

2 Sandford-Smith JH, Whittle HC. Corneal ulceration following measles in Nigerian children. Br $\mathcal{F}$ Ophthalmol 1979; 63: $720-4$.

3 Whittle HC, Sandford-Smith JH, Kogbe OI, Dossetor J, Duggan M. Severe ulcerative herpes of the mouth and eye following measles. Trans R Soc Trop Med Hyg 1979; 73: 669.

O'Day DM, Jones BR. Herpes simplex keratitis. In: Tasman W, ed. Duane's clinical ophthalmology, Lippincott: Philadelphia, 1989: Vol 4, Chapter 19.

5 Foster A, Yorston D. Corneal ulceration in Tanzanian children: relationship between measles and vitamin A deficiency. Roy Soc Trop Hyg Med (in press).

6 Yorston D, Foster A. Corneal ulceration in Tanzanian children: relationship between malaria and herpes simplex keratitis. Roy Soc Trop Hyg Med (in press)

7 Caroll JM, Martola EM, Laibson PR, Dohlman CH. The recurrence of herpetic keratitis following idoxuridine therapy. Am f Ophthalmol 1969; 63: 103-7.

8 World Health Organisation. Inter-regional workshop on the prevention of childhood blindness. WHO/PBL 1990. 19, Geneva.

9 Chirambo MC, BenEzra D. Causes of blindness among students in blind school institutions in a developing country. students in blind school institutions in a developing country. 10 Brf Ophthalmol 1976; 60: 655-8.

Africa's 3 million curably blind? Lancet 1991; 337: 1267-9.

11 World Health Organisation. Local preparation of eye drops. Geneva, 1991.

12 Coster DJ, Jones BR, Falcon MG. Role of debridement in the treatment of herpetic keratitis. Trans Ophthalmol Soc UK 1977; 97: 314-7.

13 Benvento WJ, Murray P, Reed CA, Pepose JS. The sensitivity of Neisseria gonorrhoea, Chlamydia trachomatis and herpes simplex type II to disinfection with povidone iodine. Am F Ophthalmol 1990; 109: 329-33. 